\title{
Rural provider attitudes toward the use of social media for patient engagement and retention: a brief report
}

\begin{abstract}
Background: Rural clients and providers function with many barriers in place not necessarily barriers in urban settings. Common barriers to accessing healthcare services in rural communities include financial means to pay for services, distance to provider (transportation, the need to take time off of work), ability to communicate needs to healthcare providers, ability to utilize services without compromising privacy, and confidence in the quality of care they will receive. The use of social media in rural health services can be a tool to effectively reduce or eliminate some of these barriers for patients and providers. To determine feasibility of provider's willingness or belief social media can be used in patient services, it is important to track and identify current attitudes of providers toward the use of social media in rural settings.
\end{abstract}

Objective: The purpose of the study was to identify the attitudes and beliefs of healthcare providers in rural areas toward social media use as a means to improve patient engagement and retention in several domains of services.

Methods: The authors collected the rural provider data from a nationwide survey of healthcare providers towards the use of social media in patient services $(N=1,469)$. A subset of providers that identified themselves as working in rural areas was used for data analysis purposes. Data was collected electronically through survey questions disseminated through various alumni associations, professional association list serves, and university or college "email blasts". The survey solicited attitudes towards social media use in patients services across several domains. The authors analyzed the factor structure of the social media scale (including the following areas)
i. Personal Records
ii. Billing
iii. Prescriptions
iv. Support Groups
v. Communications with family
vi. Communication with employers
vii. Current healthcare information updates
viii. Healthcare policy updates
ix. Insurance/Medicaid/Medicare information
$\mathrm{x}$. Current disease and healthcare occurrence information specific to client's personal conditions or ailments

Volume 6 Issue 6 - 2017

\author{
Gage Stermensky,' Stacy Ogbeide ${ }^{2}$ \\ 'Postdoctoral Resident, USA \\ ${ }^{2}$ Department of Family and Community Medicine, University of \\ Texas Health Sciences Center San Antonio, USA
}

Correspondence: Gage Stermensky II, Postdoctoral Resident, Hazelden, St. Paul, 680 Stewart Ave, St. Paul, MN 55 102, USA, Email gstermensky@hazeldenbettyford.org

Received: December 07, 2016 | Published: May 04, 2017

Results: Overall, providers demonstrated support for the utilization of social media. Analysis of the factor structure of the survey indicated two distinct factors, one for personal, protected information and another for social networking, compliance, outreach, and information dissemination. Providers were more likely to support social media utilization in healthcare services for the second factor. Exploration of the qualitative data indicate a perceived need for an enhanced role for mental health services (including access, policy, insurance coverage, length of treatment, and appropriate referrals made by medical professionals when necessary), more population based, preventative services, and different methods of holding patients accountable for compliance. Providers demonstrated overall advocacy for the utilization of social media.

Conclusions: While a majority of practitioners support the use of social media in patient services (for the second factor), privacy, HIPPA, ethical, and other concerns are prevalent. The author concludes by discussing training implications, future directions for healthcare policy, and the need for regulatory bodies to invest time in developing social media policies and best practices.

Keywords: internet, social media, social networking, engagement, provider attitudes, new technologies, health communication, rural

in health care. For example, social media has been used to improve child maltreatment prevention and family engagement in treatment. ${ }^{5}$

Social media usage increases in urban settings due to improved internet connections whereas in rural settings, there is a negative association with computer access and use. This can be attributed to variables such as poor internet connections (e.g., dial-up). Because of this, this can limit the usage of social media platforms by rural residents, despite that added health benefits and improved engagement and retention in urban and suburban communities. Despite the proposed setbacks to the use of information technology, rural residents may be open to its use to gain access to necessary health services. ${ }^{6}$ The use of social media has also been an area of importance for patien engagement due to the increased use of technology and telemedicine

Patient engagement in treatment within rural communities has
been found to be difficult for a variety of factors. For example, these underserved areas display a shortage in medical and behavioral health providers which can impact patient access to health care. Also, stigma regarding the treatment of certain conditions (e.g., depression, sexually transmitted infection) also hinders patient engagement with time-sensitive treatment. ${ }^{1,2}$ Research has shown that the use of telemedicine, especially in rural primary care settings, has been able engement due to the increased 
As research evolves to demonstrate the usefulness of social media platforms in health care, it is not only of importance to assess patient attitudes towards usage, but provider attitudes as well. For example, Reed et al., ${ }^{7}$ compared the acceptability of telehealth services to the acceptability of social media in rural communities and concluded that as technology becomes more common in rural health care, socia media use may increase as well as positive attitudes towards the use of technology. Jameson et al., ${ }^{8}$ found that mental health providers welcomed the use of tele-mental health services in clinics serving veterans. Nkosi, Asah, and Pillay ${ }^{9}$ examined attitudes towards technology among nursing students and found that students expressed positive attitudes towards the use of technology. The authors posit that positive attitudes in trainees may continue into post-graduate practice with continued exposure. Sukums et al., ${ }^{10}$ also found that although rural health care providers had limited exposure to technology, providers welcome continued training and education to improve their computer skills.

The use of social media as a method of communication has increased dramatically in the United States in the 21st century. With increased pressure on rural healthcare providers for population based, patient centered services, low-cost and high-reach methods of communication are a useful way to enhance shared decision making and health literacy in healthcare services. Although there is research on provider attitudes toward use of computer technology, little is known regarding rural health provider attitudes toward social media use for healthcare services. In addition, little is known regarding rural provider attitudes toward healthcare reform, and how these attitudes influence patient services in healthcare settings. Thus, the research question for this study is this: What are rural healthcare provider attitudes toward the use of social media for patient engagement and retention?

\section{Methods}

This mixed methods, exploratory study ascertained provider attitudes (from a multidisciplinary sample, including nurses, medical doctors, psychologists, social workers, counselors, paraprofessionals, among others) toward the use of social media in the current healthcare system. The authors also assessed current attitudes towards the healthcare system, including healthcare reform and ethical and professional risks related to the use of social media in healthcare related services. Data was collected electronically through open and closed ended survey questions disseminated through various alumni associations, professional association list serves, and university or college "email blasts". Table 1 displays the demographic characteristics of the participants of the study.

\section{Results}

Participants from rural areas displayed an overall negative attitude toward healthcare reform and the current healthcare system. Exploration of the qualitative data indicate a perceived need for an enhanced role for mental health services (including access, policy, insurance coverage, length of treatment, and appropriate referrals made by medical professionals when necessary), more population based, preventative services, and different methods of holding patients accountable for compliance. Providers demonstrated overall advocacy for the utilization of social media. Table 2 contains the qualitative data from the study participants.

The researcher attempted to determine the underlying factor structure of the items used for each of the healthcare reform and social media scales. As several of the items from each intended scale were at least moderately correlated with items on the other scale, an oblique rotation was employed. The analysis utilized a Principal Axis Factor Rotation with a matrix rotation to generate oblique factors. The sample was split into random halves to utilize a split sample validation as proposed by Osborne and Fitzpatrick. ${ }^{11}$ The validation compares the squared difference between each sample's factor loadings. Squared difference above 0.04 is considered indicative of a volatile factor structure for purposes of this study. Each participant was randomly assigned to the 0 or 1 grouping. The researcher utilized all seventeen Likert scale items for factor extraction (Table 3). An examination of the Kaiser-Meyer Olin measure of sampling adequacy indicates the sample is sufficient for factor analysis $(K M O=0.91)$. Bartlett's Test of Sphericity indicates the sample is adequately related for an analysis of factor structure $(X 2=1225.52, d f=45, p<0.001)$.

Table I Demographic Characteristics of Participants $(\mathrm{N}=234)$

\begin{tabular}{|c|c|c|}
\hline Characteristic & $\mathbf{n}$ & $\%$ \\
\hline \multicolumn{3}{|l|}{ Gender } \\
\hline Female & 205 & 87.6 \\
\hline Male & 29 & 12.4 \\
\hline \multicolumn{3}{|l|}{ Age at time of Survey (years) } \\
\hline $18-25$ & 17 & 7.3 \\
\hline $26-34$ & 49 & 20.9 \\
\hline $35-44$ & 39 & 16.7 \\
\hline $45-54$ & 65 & 27.8 \\
\hline $55-64$ & 56 & 23.9 \\
\hline 65 or older & 8 & 3.4 \\
\hline \multicolumn{3}{|l|}{ Highest education level completed } \\
\hline Some high school & 0 & 0 \\
\hline High school & 0 & 0 \\
\hline Some college or technical school & 16 & 6.8 \\
\hline Undergraduate & 127 & 54.3 \\
\hline Post-graduate or professional & 89 & 38 \\
\hline Prefer not to say & 2 & 0.9 \\
\hline \multicolumn{3}{|l|}{ Annual income (\$) } \\
\hline$<\$ 15,000$ & 10 & 4.3 \\
\hline$\$ 15,000-\$ 24,999$ & 10 & 4.3 \\
\hline$\$ 25,000-\$ 49,999$ & 32 & 13.7 \\
\hline$\$ 50,000-\$ 74,999$ & 56 & 23.9 \\
\hline$\$ 75,000+$ & 126 & 53.8 \\
\hline
\end{tabular}


Table Continued...

\begin{tabular}{lll}
\hline Characteristic & $\mathbf{n}$ & $\%$ \\
\hline Marital status & 31 & 13.2 \\
Single never married & 154 & 65.8 \\
Married w/o children & 31 & 13.2 \\
Married w/ children & $\mathrm{I}$ & 0.4 \\
Divorced & 3 & 1.3 \\
Separated & 14 & 6 \\
Living w/ partner & & 22.2 \\
Integrated Healthcare Setting Experience & 52 & 54.3 \\
I have worked in an integrated healthcare setting in the past & 127 & 23.5 \\
I currently work in an integrated healthcare setting & 55 & 74.8 \\
I have never worked in an integrated healthcare setting & & 7.3 \\
Health Service Provider Status & 175 & 13.2 \\
Current Health Service Provider & 17 & 3.4 \\
Health Service Provider in Training & 31 & 1.3 \\
Current Health Service Provider and Health Service Student & 8 & 3 \\
Educator/Researcher & & 3 \\
Administration/Other & & \\
\hline
\end{tabular}

Table 2 Participant Qualitative Feedback

\begin{tabular}{|c|c|c|}
\hline $\begin{array}{l}\text { Question } \\
\text { healthcare reform }\end{array}$ & Themes & Subthemes \\
\hline \multirow[t]{3}{*}{$\begin{array}{l}\text { Explain what an ideal healthcare system would } \\
\text { look like in America }\end{array}$} & Systemic & $\begin{array}{l}\text { Approval procedures, policy maker fidelity, costs, access, health promotion } \\
\text { and preventative focus, integrated system, standardized electronic record } \\
\text { system }\end{array}$ \\
\hline & Providers & Training, compensation, quality, policy \\
\hline & Patients & $\begin{array}{l}\text { Accessibility (location, choices, costs), accountability (of adherence and } \\
\text { compliance), improved informed consent }\end{array}$ \\
\hline \multirow{3}{*}{$\begin{array}{l}\text { What role should mental health treatment play } \\
\text { in the healthcare system? How does the new } \\
\text { role need to differ from its current role? }\end{array}$} & Parity & common "health" (not physical vs. mental), reimbursement, coverage \\
\hline & Integration & $\begin{array}{l}24 / 7 \text { emergency room services, long-term care and terminal diseases } \\
\text { lacking }\end{array}$ \\
\hline & Stigma & Earlier screening and education \\
\hline \multirow{7}{*}{$\begin{array}{l}\text { Social Media } \\
\text { What are the pros of using social media in } \\
\text { healthcare }\end{array}$} & & \\
\hline & None & \\
\hline & Inexpensive & More material \\
\hline & Reach & $\begin{array}{l}\text { Younger, faster, more information, more venues (twitter, Facebook, etc.), } \\
24 / 7 \text { availability, multiple devices }\end{array}$ \\
\hline & Interactive & Family, friends, educational, communication, support groups \\
\hline & Quality & Information source, research or evidence behind information \\
\hline & Privacy & HIPAA, Theft, Fraud \\
\hline \multirow{3}{*}{$\begin{array}{l}\text { What are the cons of using social media in } \\
\text { healthcare? }\end{array}$} & Better Options & EMR, email \\
\hline & Risk Patients & to Referral if information causes crisis or needed services for the patient \\
\hline & Limited Reach & Elderly, information lost in shuffle of other social media information \\
\hline \multirow[t]{2}{*}{ What role should social media play in healthcare? } & $\begin{array}{l}\text { Compliance/ } \\
\text { Adherence }\end{array}$ & Medications, appointments, homework, assessment, reminders \\
\hline & $\begin{array}{l}\text { Education } \\
\text { Marketing }\end{array}$ & $\begin{array}{l}\text { Health promotion, shared decision making, diseases, Healthcare reform and } \\
\text { policy change updates }\end{array}$ \\
\hline \multirow{3}{*}{$\begin{array}{l}\text { What are your concerns related to social media } \\
\text { uses in healthcare? }\end{array}$} & Patient & Lack of knowledge of use, easily accessible by others on social media \\
\hline & Provider & $\begin{array}{l}\text { Ethical, blurring professional and personal boundaries, use for wrong } \\
\text { purposes/profit }\end{array}$ \\
\hline & Tracking & Viruses, use information other purposes, selling information, fraud \\
\hline
\end{tabular}

The extraction resulted in five factors based upon examination of Eigen values greater than 1.0. The researcher determined, based upon consideration of Eigen values, visual evaluation of the scree plot, and relative effect size for competing models (i.e., variance explained), as well as inspection of resulting factor patterns and content (i.e., to consider number of items loaded on each factor and if there appeared to be correlated factors), to interpret two factors. Analysis of the factor structure of the survey indicated two distinct factors, one for personal, protected information and another for social networking, compliance, outreach, and information dissemination (Table 4). Providers were more likely to support social media utilization in healthcare services for the second factor.

\section{Discussion}

Healthcare providers in rural areas demonstrated an overall negative attitude towards healthcare reform. While a majority of practitioners support the use of social media in patient services (for the second factor), privacy, HIPPA, ethical, and other concerns are 
prevalent. The authors conclude by discussing training implications, future directions for healthcare policy, and the need for regulatory bodies to invest time in developing social media policies and best practices.

Table 3 Variables for Exploratory Factor Analysis

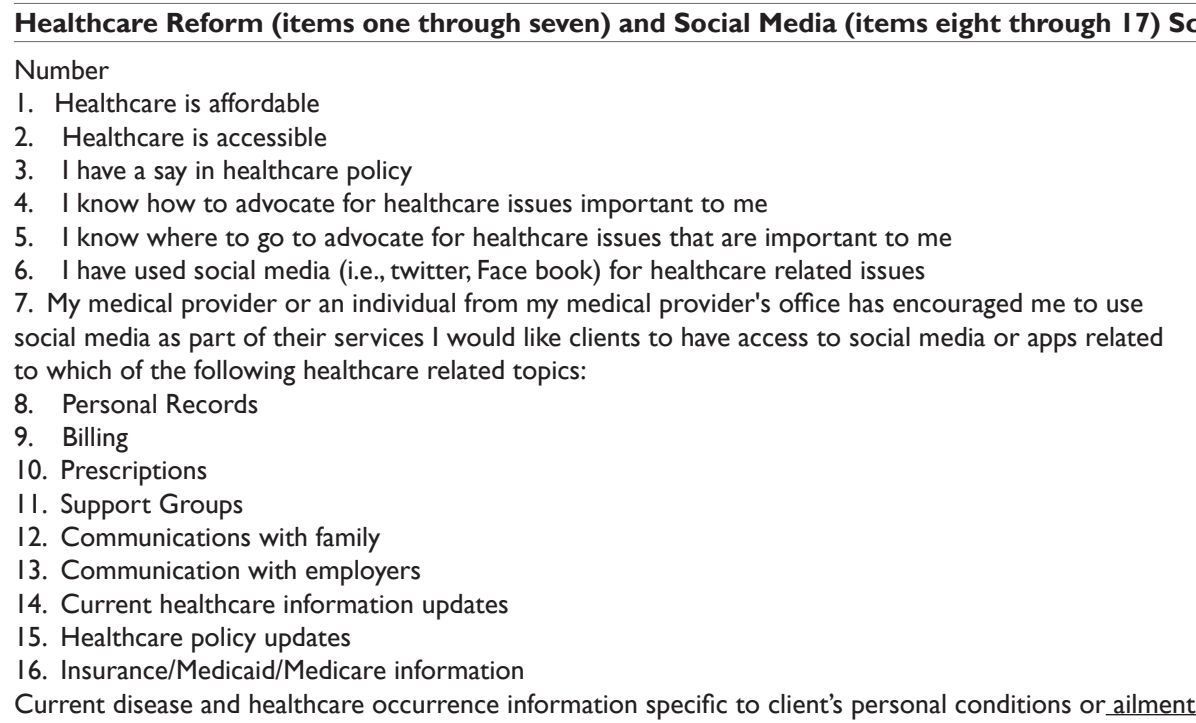

Table 4 Analysis of the factor structure of the survey indicated two distinct factors, one for personal, protected information and another for social networking, compliance, outreach, and information dissemination

\begin{tabular}{llllllll}
\hline $\begin{array}{l}\text { Question } \\
\text { Random ID = }\end{array}$ & Communality & \multicolumn{2}{l}{ Factor Load } & $\begin{array}{l}\text { Communality } \\
\text { Random ID = I }\end{array}$ & Factor Load & Squared Diff \\
\hline 15 & Extraction & $\mathbf{I}$ & $\mathbf{2}$ & Extraction & $\mathbf{I}$ & $\mathbf{2}$ & \\
11 & 0.77 & $\mathbf{0 . 9 4}$ & -0.24 & 0.82 & $\mathbf{0 . 9 7}$ & -0.15 & 0.000 \\
14 & 0.63 & $\mathbf{0 . 8 2}$ & -0.05 & 0.73 & $\mathbf{0 . 9 1}$ & -0.05 & 0.017 \\
17 & 0.73 & $\mathbf{0 . 8 0}$ & 0.11 & 0.79 & $\mathbf{0 . 8 5}$ & 0.01 & 0.000 \\
16 & 0.73 & $\mathbf{0 . 8 0}$ & 0.07 & 0.79 & $\mathbf{0 . 7 6}$ & -0.01 & 0.000 \\
12 & 0.69 & $\mathbf{0 . 7 8}$ & 0.08 & 0.64 & $\mathbf{0 . 6 3}$ & -0.08 & 0.000 \\
8 & 0.50 & $\mathbf{0 . 6 5}$ & 0.11 & 0.78 & $\mathbf{0 . 6 3}$ & 0.27 & 0.002 \\
9 & 0.85 & -0.04 & $\mathbf{0 . 9 2}$ & 0.81 & 0.35 & $\mathbf{0 . 9 6}$ & 0.002 \\
10 & 0.95 & 0.14 & $\mathbf{0 . 9 0}$ & 0.70 & 0.04 & $\mathbf{0 . 8 1}$ & 0.008 \\
13 & 0.82 & 0.34 & $\mathbf{0 . 6 2}$ & 0.70 & -0.01 & $\mathbf{0 . 7 4}$ & 0.014 \\
\hline
\end{tabular}

While there was a lack of provider support for all categories and purposes of social media use, most providers endorsed at least some methods of social media as being useful in health service provision. These areas are consistent with previously researched areas, such as policy, appointment reminders, support groups for patients and family members, and education/psycho education. The more personal or HIPAA protected the information, the less likely participants were to endorse the item to be used by patients. This was evident in the factor structure of the social media scale score, with factor one comprised of less protected data, and factor two more personal and protected data. Until protections and safeguards are in place, the authors agree with the participants that such information is better integrated into electronic medical record and portals on provider websites. The divide was also consistent throughout the qualitative data. Methods of use supported include: appointment reminders, family communication, support groups, medication compliance, education, and health promotion/ psycho education are supported. ${ }^{12}$

\section{Conclusions}

More clearly defined and transparent guidelines and by-laws are needed from various regulatory bodies and state licensure committees to guide practitioners in the future. In addition, effective ways to disseminate the identified benefits of social media use (especially for healthcare policy related information) to providers is an area of future research need. Identifying more concise provider characteristics and opinions about specific social media utilization will also be important moving forward. Providing education on the success various programs have had will hopefully increase support and advocacy for the use of the ever-increasing form of communication that reaches both pediatric and geriatric patients.

The authors recommend social media training, with a required certificate, for all healthcare professionals through their educational institutions, and social media presence and education of grade school children. Framing these endeavors around health literacy enhancement and the goals to increase informed, competent, and educated consumers (and providers) can result in accurate shared decision making. Such patients would be more likely to follow up on recommendations of providers and enhances billing and accountability of service continuity. Of concerns to many providers, are the lack of access and an uninformed patient base. What better way than an inexpensive, frequently utilized method of communication available to every patient in their purse, pocket, or car? If the field decides not to grow, it will not thrive. 
Limitations of this study include the use of novel instruments additional qualitative data coders or qualitative analysis software could improve the usefulness and utility of the qualitative results. There was a disproportionate number of RNs in the study. In addition, the sample represents a high pay and educational attainment portion of the overall healthcare provider sample.

\section{Acknowledgments}

None.

\section{Conflicts of interest}

Author declares there are no conflicts of interest.

\section{Funding}

None.

\section{References}

1. http://www.hrsa.gov/advisorycommittees/rural/2010secretaryreport.pdf

2. Smalley KB, Yancey CT, Warren JC, et al. Rural mental health and psychological treatment: A review for practitioners. $J$ Clin Psychol. 2010;66(5):479-489.

3. Brenes GA, Danhauer SC, Lyles MF, et al. Telephone-delivered psychotherapy for rural-dwelling older adults with generalized anxiety disorder: Study protocol of a randomized controlled trial. BMC Psychiatry. 2014;14:34.

4. Callas PW, McGowan JJ, Leslie KO. Provider attitudes toward a telepathology program. Telemedicine Journal. 1996;2(4):319-329.
5. Edwards-Gaura A, Whitaker D, Self-Brown S. Can social networking be used to promote engagement in child maltreatment prevention programs? Two pilot studies. West J Emerg Med. 2014;15(5):575-581.

6. Dunkley C, Pattie L, Wilson L, et al. A comparison of rural speechlanguage pathologists' and residents' access to and attitudes towards the use of technology for speech-language pathology service delivery. Int $J$ Speech Lang Pathol. 2010;12(4):333-343.

7. Reed RN, Messler EC, Coombs TE, et al. Social media use and the acceptability of telepsychological services in rural populations. Journal of Rural Mental Health. 2014; 38(1):2-8.

8. Jameson JP, Farmer MS, Head KJ, et al. VA community mental health service providers' utilization of and attitudes toward telemental health care: The gatekeeper's perspective. J Rural Health. 2011;27(4):425-432.

9. Nkosi ZZ, Asah F, Pillay P. Post-basic nursing students' access to and attitudes toward the use of information technology in practice: A descriptive analysis. J Nurs Manag. 2011;19(7):876-882.

10. Sukums F, Mensah N, Mpembeni R, et al. Health workers' knowledge of and attitudes towards computer applications in rural African health facilities. Global Health Action. 2014;7:24534.

11. Osborne JW, Fitzpatrick DC. Replication Analysis in Exploratory Factor Analysis: What it is and why it makes your analysis better. Practical Assessment, Research \& Evaluation. 2011;17(15):1-8.

12. Stermensky G. Provider attitudes toward the use of social media in patient care: An exploratory study. Springfield, USA: Psy Degree Dissertation. The School of Professional Psychology at Forest Institute; 2014. 